\title{
Comparative Study of Esophageal Varices Grading by Multi- Detector Computed Tomography and Endoscopy
}

\author{
FATMA A. EL-SHARAWY, M.D.* and MOHAMED M. MABROUK, M.D.** \\ The Departments of Radio-Diagnosis \& Medical Imaging* and Internal Medicine**, Faculty of Medicine, \\ Tanta University, Egypt
}

\begin{abstract}
Background: Cirrhosis is often complicated by Esophageal Varices (EV) and portal hypertension. The use of upper GI endoscopy (GIE) as a screening method is limited regarding invasiveness, expensive, needs sedation as well as patient's poor acceptance of the procedure. In contrast; Multidetector Computed Tomography (MDCT) imaging is non-invasive, does not necessitate sedation, and allows accurate assessment of variceal site and size, also better tolerated by patients than upper GI Endoscopy (GIE).
\end{abstract}

Aim of Study: To prove that MDCT is a non-invasive alternative diagnostic tool to EGD in grading of Esophageal Varices.

Patients and Methods: 50 patients with liver cirrhosis were included. Evaluation of Multidetector Computed Tom- ography (MDCT) in the diagnosis of esophageal varices and its grading was done by comparing the grades of Esophageal Varices at Multidetector Computed Tomography (MDCT) and upper GI endoscopy independently. Extra-esophageal findings were also assessed by Multidetector Computed Tomography (MDCT) that cannot by (GIE).

Results: At upper GI endoscopy, 3 patients had grade 0 Esophageal Varices, 25 patients had grade 1, 16 patients had grade 2 and 6 had grade 3 . The sensitivity, specificity, positive and negative predictive values and accuracy of Multidetector Computed Tomography (MDCT) for defining Esophageal Varices in all grades were 99.5\%, 99.6\%, 99.4\%, 99.5\% and 99.5\% respectively. Important extra-esophageal findings were determined by Multi-Detector Computed Tomography (MDCT) only. The acceptance of patients for Multidetector Computed Tomography (MDCT) was significantly more than that for upper GI Endoscopy (GIE).

Conclusion: Multi-Detector Computed Tomography (MD- CT) is a fast, non-invasive procedure for diagnosis and grading of Esophageal Varices.

Key Words: Esophageal Varices (EV) - Upper GI endoscopy (GIE) - Computed Tomography (CT) - Multidetector Computed Tomography (MDCT) Esopha- go-Gastro-Duodenoscopy (EGD) Intra-Venous (IV).

Correspondence to: Dr. Fatma A. El-Sharawy,

E-Mail: elsharawyf@hotmail.com

\section{Introduction}

Development of significant complications for portal hypertension as ascites and/or Esophageal and Gastric Varices occurs when hepatic venous pressure gradient increases above 10mmHg [1] .

Esophageal varices is one of the major compli- cations of liver cirrhosis, with an estimated preva- lence of approximately $80 \%$ with decompensated patients and $50 \%$ in compensated cirrhosis [2] .

Esophagoscopy (EGD) is the gold standard in the diagnosis of oesophageal Varices; however, the use of endoscopy as a method of screening is limited, as it is invasive, expensive, needs sedation together with patient's poor acceptance of the procedure [3] .

Several studies have searched for alternatives to conventional endoscopy including biochemical, clinical and ultrasound parameters, transient elastography and video capsule endoscopy for the non-invasive or minimally invasive diagnosis of oesophageal Varices. These methods have shown promising performance characteristics for overcoming bleeding and were perceived by patients as preferable to endos- copy; yet they have limited sensitivity and specif- icity and none of them had been proved as an alternative for upper GI endoscopy [4] .

CT imaging as better tolerated by most of the patients ,non-invasive, does not need sedation, and allows accurate assessment of variceal site and size than endoscopy is considered a good alternative to upper GI endoscopy [5] . 
With the introduction of MDCT imaging with its multi-planar capabilities, esophageal, para- esophageal and Gastric Varices as well as other porto-systemic shunts was progressively recognized in patients with liver cirrhosis [6] .

Aim of the study: To prove that MDCT is a non-invasive alternative diagnostic tool to EGD in grading of Esophageal Varices.

\section{Patients and Methods}

This prospective study was carried out on 50 cirrhotic patients (30 males, 20 females) their age ranged from 31 to 75 years with a mean age of

49.9 years. They were referred to Diagnostic Ra- diology and Medical Imaging Department, from Internal Medicine and Tropical Medicine Depart- ments; Tanta University Hospital throughout the period from April 2018 to November 2019.

\section{Inclusion criteria:}

- Cirrhotic patients diagnosed by clinical, laboratory and radiological parameters.

- Patients suspicious to have hepatocellular carci- noma.

- Patients with portal hypertension diagnosed by abdominal ultrasonography.

\section{Exclusion criteria:}

- Active gastrointestinal bleeding.

- History of endoscopic variceal ligation.

- History of adverse reactions to iodinated contrast agent.

\section{Methods:}

The procedure was carried out over two separate studies; MDCT study with IV contrast injection and EGD study. MDCT images were evaluated for diagnosis and grading of Esophageal Varices and then correlated with EGD.

\section{1-Multidetector computed tomography (MDCT):}

All studies were obtained using a 128 multidetector CT scanner (GE Optima CT model 660) installed in Diagnostic Radiology and Medical Imaging Department. Before examination the pa- tients swallow two $5 \mathrm{~g}$ packets of effervescent powder containing sodium bicarbonate, tartaric acid and citric acid. Patients lied supine with head first. Scout films were taken routinely in all patients.

MDCT was performed before and after the injection of non-ionic contrast medium. No positive oral contrast material was administered. After completion of the nonenhanced scans, an IV bolus injection of non-ionic contrast material was admin- istered at a dose of $1.5-2 \mathrm{mg} / \mathrm{kg}$ at a rate of $4 \mathrm{ml} / \mathrm{s}$ through a 22-gauge IV catheter inserted into an ante-cubital vein using an automatic injector.

After injection of intravenous contrast material, the liver was scanned in arterial (scanning delay, 20-25 seconds), portal (scanning delay, 60 seconds), and delayed (scanning delay, 3-5 minutes) phases. Images were performed from the lower thorax and abdomen to the iliac wing during a single breath- hold at the end of inspiration.

After completion of the study, a high-quality data set with a $0.7-\mathrm{mm}$ reconstruction interval was transferred to a picture archiving and communica- tion workstation equipped with dedicated 2D and 3D software tools which allowed processing of Multiplanar Reconstructions (MPRs) and Volume Renderings (VRs), by using surface-shaded trans- parent and endo-luminal virtual endoscopy modes.

\section{2- Esophagoscopy :}

All studies were obtained using Pentax EG2985. Esophagoscopy was done within 1 week from the MDCT study. Patients were fasting overnight. Before the procedure, Midazolam 3$5 \mathrm{mg}$ IV was given with Xylocaine local spray above the tongue and na- sopharynx. Using Pentax EG-2985, the patient lied on the examination trolley on the left side with the IV access line preferably in the right arm. The endoscope was inserted under direct vision. Exam- ination of the entire esophagus was done.

\section{Results}

Our study included 50 cirrhotic patients 30 of them were males and 20 females. Their age ranged from 31 to 75 years with a mean of 49.9 years. (Table 1) shows the different age groups. 
Table (1): Age and sex distribution in the studied patients $(\mathrm{n}=50$ patients).

\begin{tabular}{lccc}
$\begin{array}{l}\text { Age group } \\
\text { (years) }\end{array}$ & \multicolumn{2}{c}{ Sex } & Total \\
& Male & Female & \\
\hline $30-39 Y$ & 0 & 1 & 1 \\
$40-49 Y$ & 11 & 9 & 20 \\
$50-59 Y$ & 16 & 9 & 25 \\
$60-69 Y$ & 1 & 1 & 2 \\
$70-80 Y$ & 2 & 0 & 2 \\
\hline Total & 30 & 20 & 50 \\
\hline
\end{tabular}

The causes of liver cirrhosis were different among the studied patients, 13 had hepatitis B (26\%), 26 had hepatitis C (52\%), 11 had Bilharzia- sis \& other causes of cirrhosis (22\%). The different causes of cirrhosis are shown in Fig. (1).

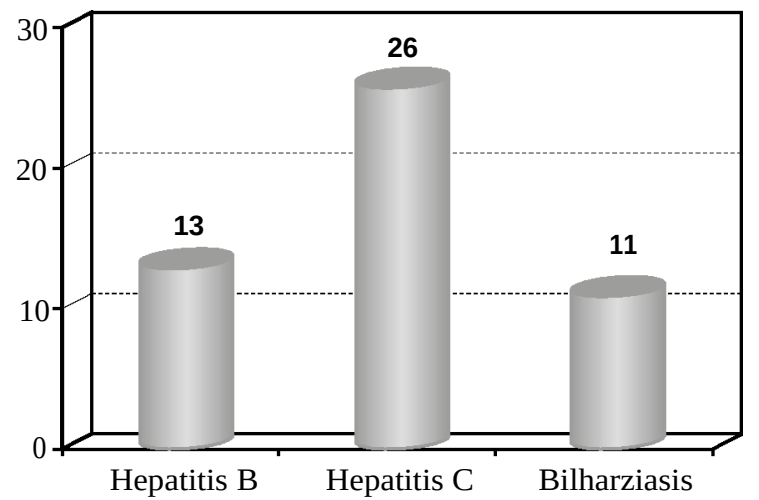

Fig. (1): Causes of liver cirrhosis in the studied patients ( $n=50$ patients).

In our study, Esophageal Varices were classified into four groups by MDCT:

Grade 0: No Varices visualization on the inner surface of the Esophagus.

Grade 1: One varix less than $5 \mathrm{~mm}$ in diameter detected on the inner surface from the esophagus.

Grade 2: Several Varices less than $5 \mathrm{~mm}$ detect- ed on the inner surface from the esophagus.

Grade 3: One varix $5 \mathrm{~mm}$ or greater or several Varices occupy more than half of the circumfer- ence of the Esophagus. The results are listed in (Table 2).

Table (2): MDCT grades of Esophageal Varices in the studied patients ( $\mathrm{n}=50$ patients).

\begin{tabular}{lcc}
\hline Grade & No. of patients & Percentage \\
\hline Grade 0 & 3 & 6 \\
Grade 1 & 25 & 50 \\
Grade 2 & 16 & 32 \\
Grade 3 & 6 & 12 \\
\hline Total & 50 & 100 \\
\hline
\end{tabular}

In our study, Esophageal Varices were classified into four groups by EGD:

Grade 0: No Varices visualization on the inner surface of the esophagus.

Grade 1: Small Varices were defined as those that flatten with insufflations or protrude minimally into the esophageal lumen.

Grade 2: Moderate-sized Varices were defined as those that protrude into the esophageal lumen but did not touch each other.

Grade 3: Large Esophageal Varices were defined as those that protrude into the Esophageal lumen and touch each other. The results are listed in (Table 3).

Table (3): Endoscopic grades of Esophageal Varices in the studied patients ( $\mathrm{n}=50$ patients).

\begin{tabular}{lcc} 
& No. of patients & Percentage \\
\cline { 2 - 3 } Grade & 3 & 6 \\
Grade 0 & 25 & 50 \\
Grade 1 & 17 & 34 \\
Grade 2 & 5 & 10 \\
Grade 3 & 50 & 100 \\
\hline Total & & \\
\hline
\end{tabular}

The ability of MDCT and Virtual Endoscopic CT to identify Esophageal Varices (EV) as compared to EGD was listed in (Table 4).

Table (4): MDCT and virtual endoscopic CT compared to endoscopy to identify Esophageal Varices.

\begin{tabular}{lcccc}
\hline Grades & Grade0 & GradeI & Grade II & GradeIII \\
\hline True positive & 3 & 24 & 17 & 5 \\
True negative & 47 & 26 & 33 & 45 \\
False positive & 0 & 0 & 1 & 0 \\
False negative & 0 & 1 & 0 & 0
\end{tabular}

Table (5): sensitivity, specificity and accuracy of MDCT and Virtual Endoscopic CT to identify Esophageal Varices as referred to endoscopy.

\begin{tabular}{lccccc}
\hline & Sensitivity & Specificity & PPV & NPV & Accuracy \\
\hline Grade 0 & 100 & 100 & 100 & 100 & 100 \\
\hline Grade 1 & 98 & 100 & 100 & 98.1 & 99 \\
\hline Grade 2 & 100 & 98.5 & 97.1 & 100 & 99 \\
\hline Grade 3 & 100 & 100 & 100 & 100 & 100 \\
\hline Total & 99.5 & 99.6 & 99.4 & 99.5 & 99.5 \\
\hline
\end{tabular}

The sensitivity, specificity, positive and negative predictive values and accuracy of CT for defining $\mathrm{EV}$ in all grades were 99.5\%, 99.6\%, 99.4\%, 99.5\% and $99.5 \%$ respectively. 
In our study, we identified extra-esophageal pathology by multi-detector MDCT only. The different findings are showed in (Table 6).

Table (6): Extra-esophageal findings identified by MDCT in the studied patients ( $n=50$ patients).

\begin{tabular}{lcc}
\hline CT extra-esophageal findings & No. of patients & Percentage \\
\hline HCC & 4 & 8 \\
Splenomegaly & 37 & 74 \\
Ascites & 31 & 62 \\
Para-esophageal varices & 29 & 58 \\
Gastric varices & 23 & 46 \\
Perisplenic collateral & 17 & 34 \\
\hline
\end{tabular}

In our study, when we compare the acceptance of MDCT and upper GI endoscopy techniques from the patient side, 47 patients (94\%) out of 50 found that MDCT is more preferable and accepted than upper GI endoscopy. Patient preference is shown in Fig. (2).

Fig. (2): Comparison between MDCT and endoscopy as regards patient preference.

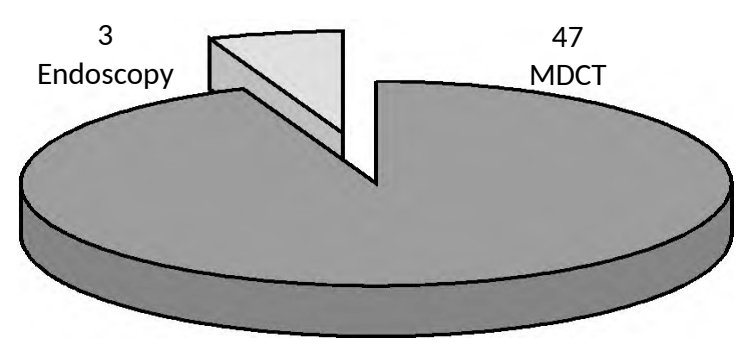



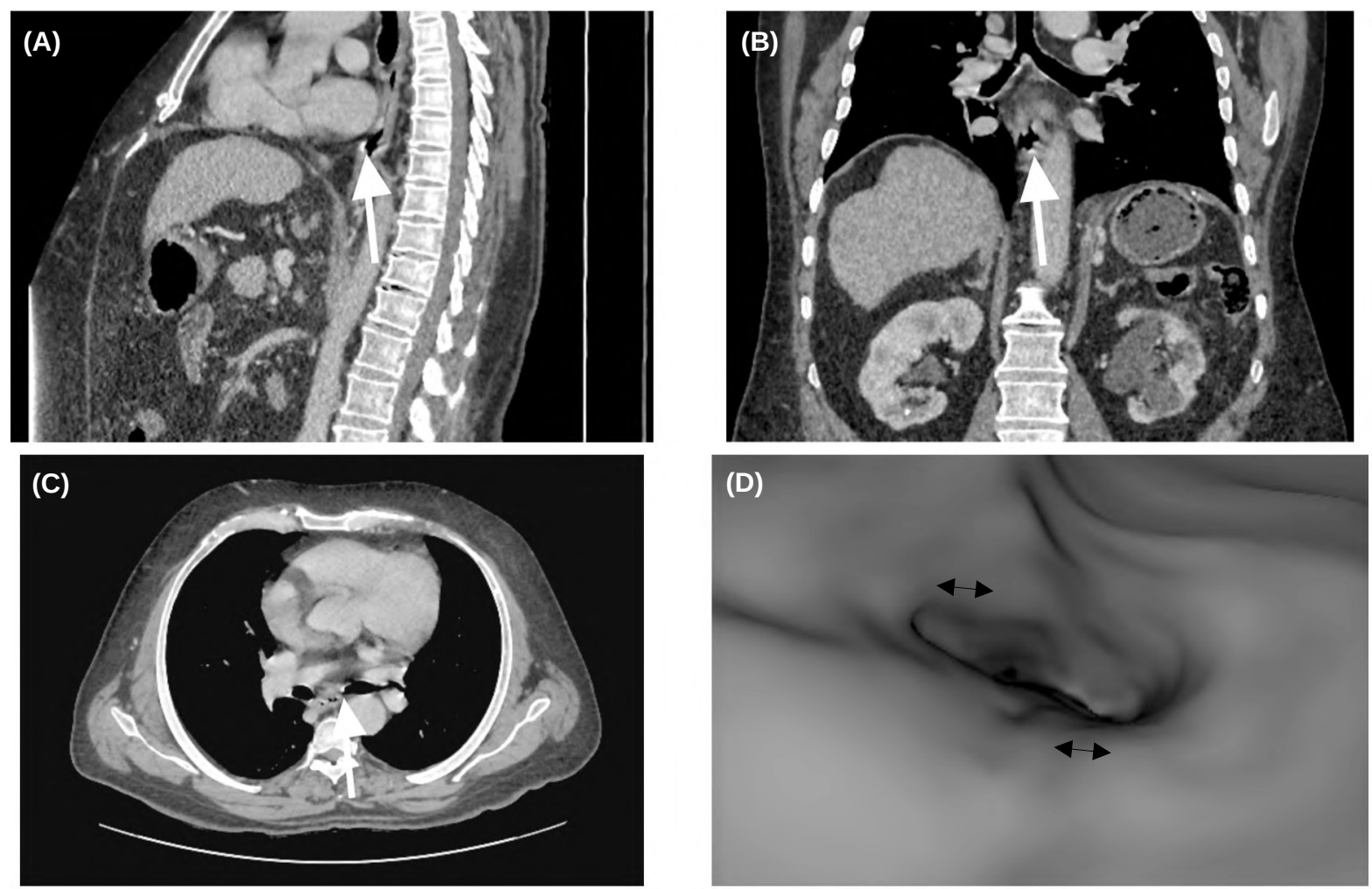

Fig. (3): Male patient aged 68 years old with hemoptysis: MDCT porto-venous phase sagittal (A), coronal (B) axial (C) and virtual CT (D) images show enhanced vessels protruded into the esophageal lumen-white arrow-(esophageal varices grade 2 by CT) measuring between 2.8-4.3mm confirmed by EGD image (E).

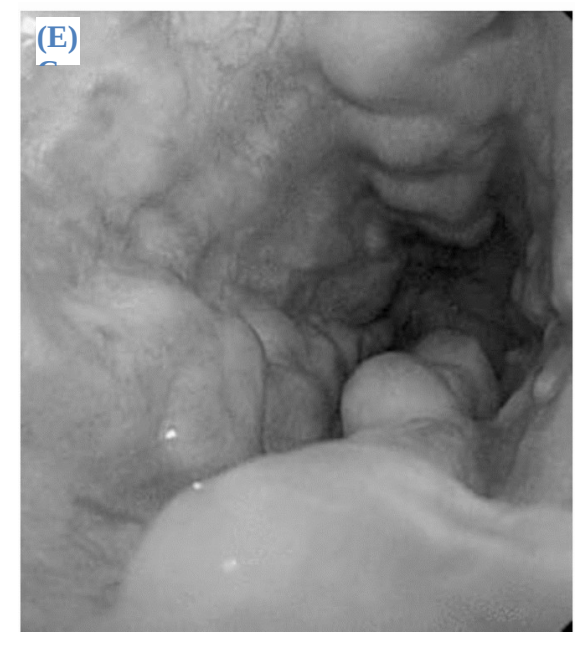

Upper endoscopy 3 days later done by professional internal medicine doctor revealed grade 3 esophageal varices.<smiles>C1C2CC1C2</smiles> 

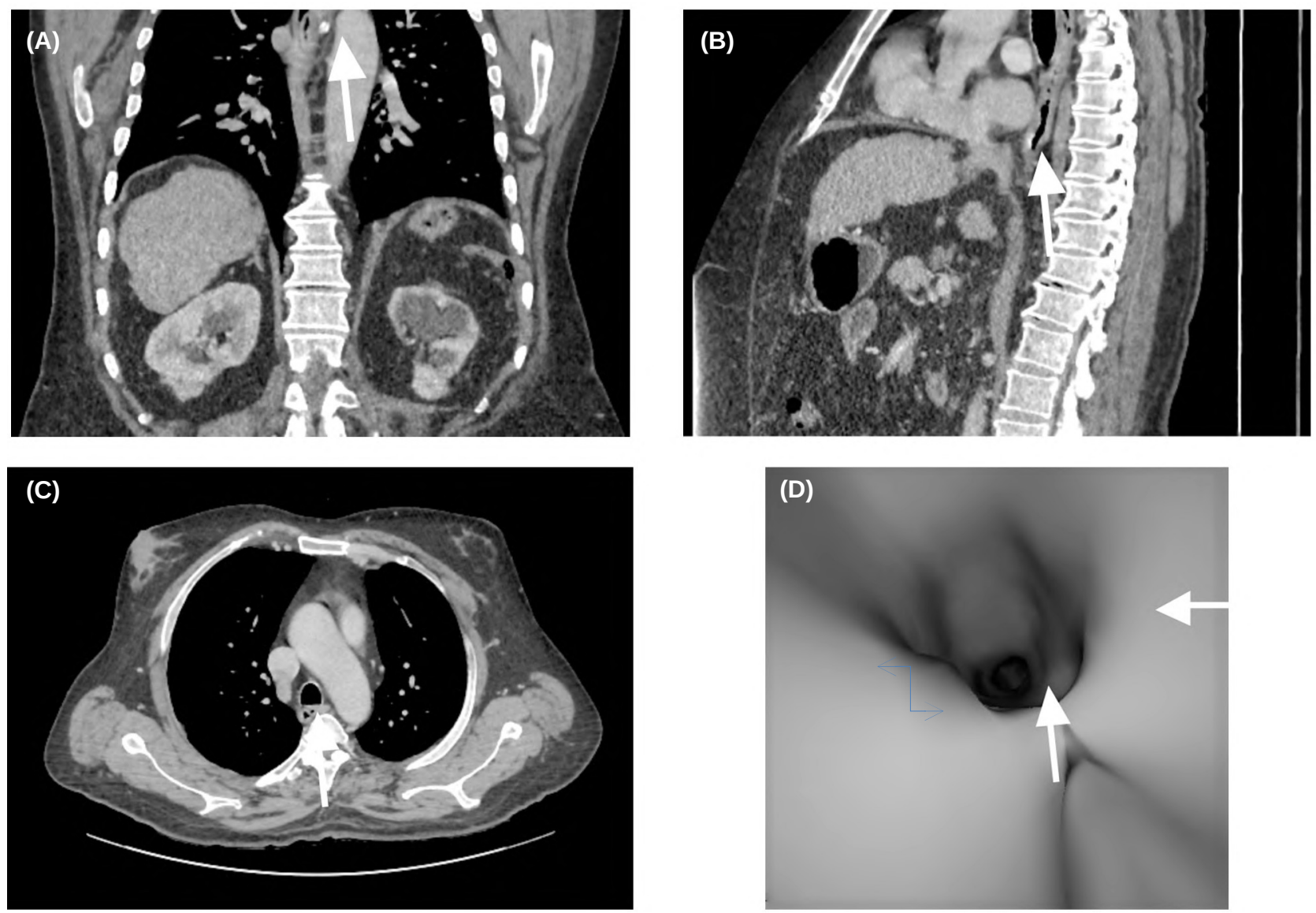

Fig. (4): Female patient aged 49 years old with recurrent hemoptysis \& U/S revealed hepatic focal lesion \& splenomegally: MDCT porto-venous phase axial coronal (A), sagittal (B), axial (C) and endoscopic (D) images show multiple enhanced vessels involving the whole circumference of the esophageal lumen-white arrow-(esophageal varices grade 3 by CT) confirmed by EGD image (E).

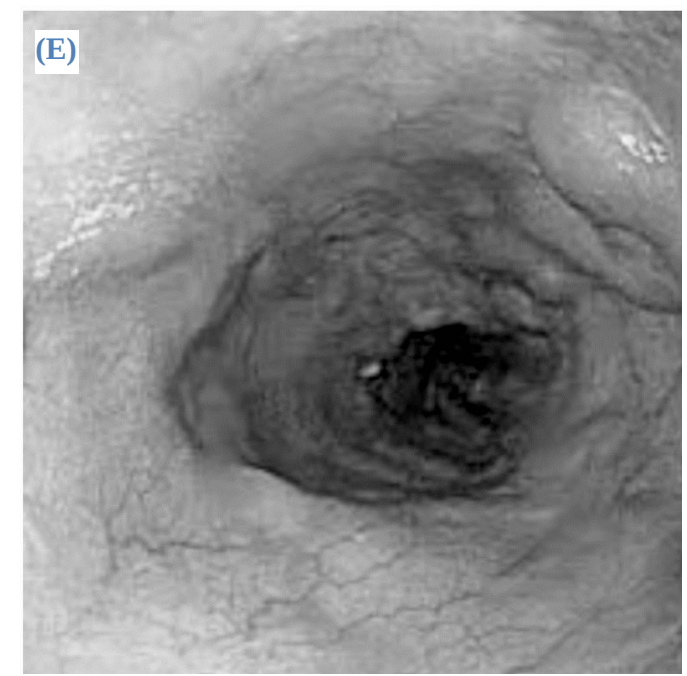

Upper endoscopy a week later done by professional internal medicine doc- tor revealed grade 2 esophageal varices.

$$
\text { 负. }
$$



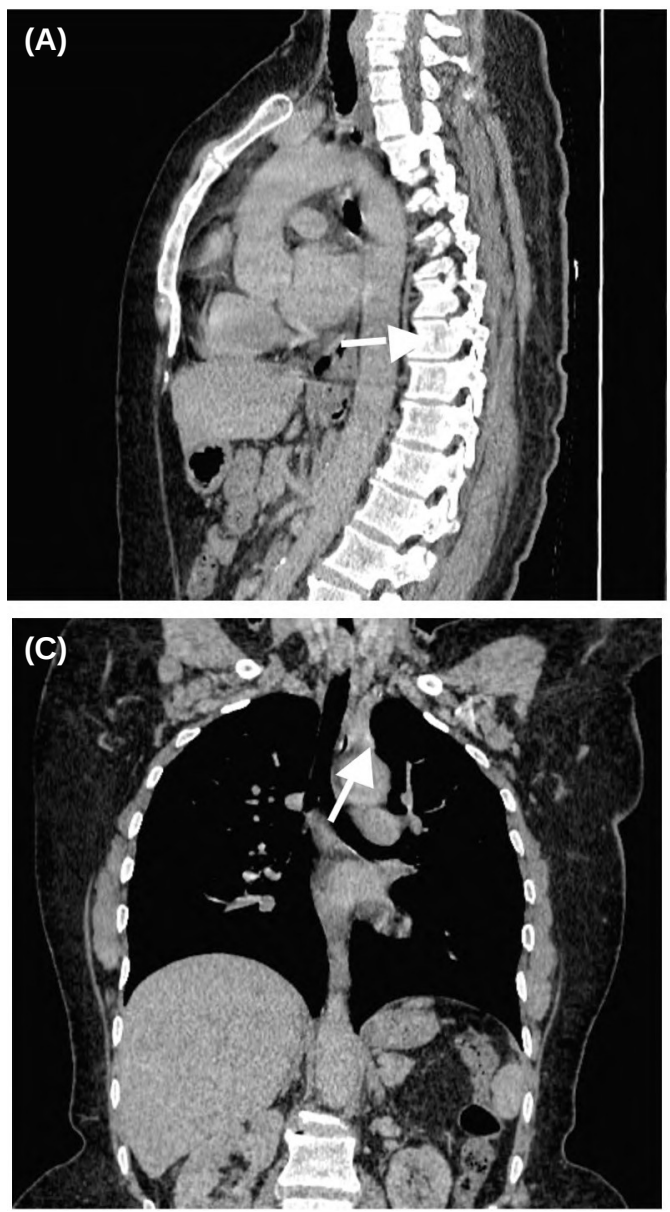
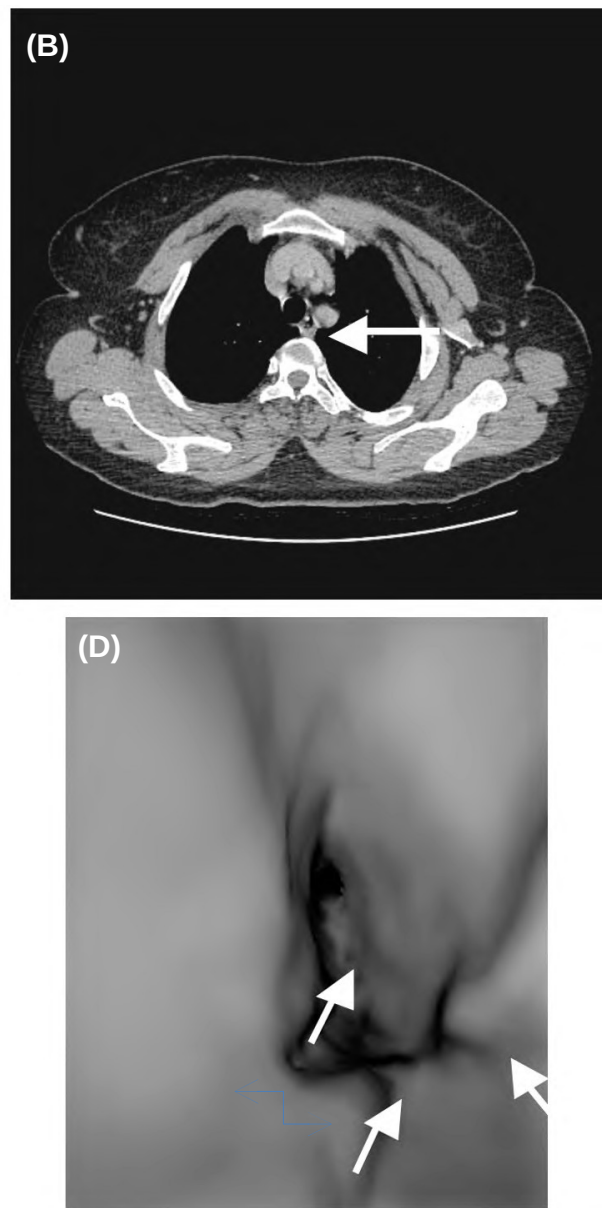

Fig. (5): Male patient aged 61 years old with recurrent hemoptysis \& pevious variceal ligation: MDCT Porto-venous phase sagittal (A), axial (B) coronal (C) and endoscopic (D) images show multiple enhanced vessels involving the whole circumference of the esophageal lumen-white arrow-(esophageal Varices score 3 by CT) confirmed by GED image (E). The liver is cirrhotic.

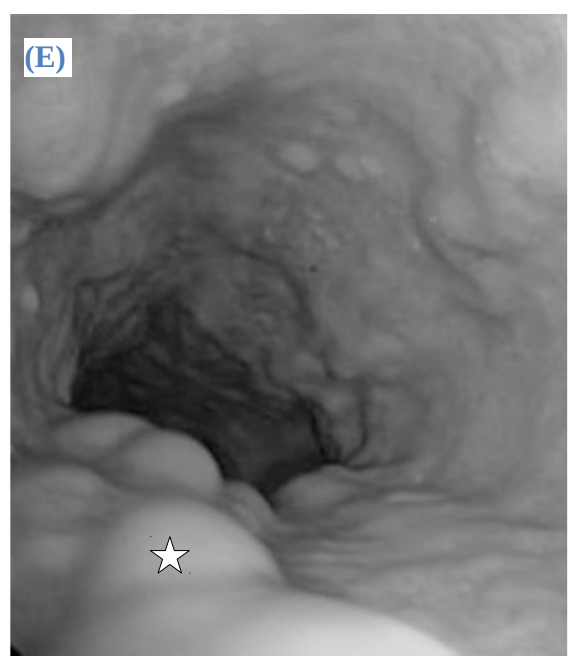

\section{Discussion}

Approximately $60-80 \%$ of patients with liver cirrhosis develop Esophageal Varices during their life at a rate of $5 \%$ per year, the progression from small to large Varices occurs in $5-10 \%$ of patients after the first year [8] .
Upper endoscopy done by professional internal medicine doctor revealed grade 3 esophageal varices.

$$
\text { 绽 }
$$

Esophagoscopy is the gold standard in the diagnosis of oesophageal Varices in cirrhotic patients [9] .

Screening for esophageal Varices using upper GI endoscopy is always done for patients with cirrhosis to avoid significant morbidity and mor- 
tality associated with bleeding from Varices [10] It is recommended every year in patients with small Varices and every 2-3 years in patients without Varices to allow initiation of primary preventive treatment, this means that a large number of cir- rhotic patients undergo unnecessary endoscopic examination [11] .

The use of upper GI endoscopy as a method of screening is limited, as it is invasive, expensive, needs sedation, and the patient's poor acceptance of the procedure [12] .

MDCT imaging is non-invasive, does not necessitate sedation, and allows accurate assessment of variceal site and size, and it is also better toler- ated by most of the patients than upper GI endos- copy [13] .

In this study we compare the ability of MDCT in the diagnosis of esophageal Varices as a non-invasive procedure and its acceptance to the patients to upper GI endoscopy. It included (50) patients with cirrhosis (30) males (60\%) and (20) females (40\%). So male affection is more predominant than females in agreement with Moftah et al. study [14] where male patients were $74 \%$ and female patients were $26 \%$.

The causes of liver cirrhosis were different among the studied patients, 13 had hepatitis B (26\%), 26 had hepatitis C (52\%), 11 had Bilharzia- sis (22\%). So hepatitis C is a major cause of liver cirrhosis in agreement with Dessouky et al. study

[15] where the most common cause of liver cirrhosis was hepatitis C (68\%).

In our study, CT scan had a sensitivity of (99.5\%), a specificity of (99.6\%). So close to that found by Dessouky et al. study [15] where the overall CT sensitivity was (99\%), and specificity (98\%), in comparison to the upper GIT endoscopy.

As regards conventional CT in diagnosis and grading of esophageal Varices; the study of Perri et al. [16] reported that CT has approximately $90 \%$ sensitivity in the detection of esophageal Varices, but only about $50 \%$ specificity. Also, Kim et al. Study [17] got results with sensitivity (92\%), spe- cificity (84\%), Dessouky et al. study [15] also reported (99\%) sensitivity, specificity (98\%) while ours recorded sensitivity (99.5\%), specificity (99.6\%).

A well optimized protocol for the evaluation of Esophageal Varices with contrast, very small slice thickness, bolus tracking technique that allows more accurate timing of arterial and portal venous phases and acquisition of high-resolution images associated with 2D and 3D reconstructions and endo-luminal virtual images that provide accurate results about different grades of Esophageal Varices. Moreover, the higher sensitivity and specificity in our study may be due to the fact that we use 128 slice MDCT while in the study of Perri et al., [16] they used 4 detectors and in Also Kim et al., [17] they used 16 detectors in their studies.

An efficient and well-tolerated technique for distending the esophagus was done by the administration of effervescent powder. The slow passage of the effervescent powder through the esophagus and the supine position of the patient save the developed gas within the esophageal lumen longer, thus causing more efficient wall distension. This was in agreement with Cansu et al. study [18] who reported that using the effervescent powder in the detection and grading of esophageal Varices by MDCT increased the success rate of MDCT. Thus, small Varices, which are difficult to be detected via MDCT, can be detected and upper GI endoscopy may not be required to evaluate these low risk bleeding Varices.

In our study, when we compare the acceptance of MDCT and upper GI endoscopy techniques from the patient side, 47 patients (94\%) out of 50 found that MDCT is more preferable and accepted than upper GI endoscopy, only 3 patients (6\%) found upper GI endoscopy more preferable. This was in agreement with Dessouky et al. [15] who reported MDCT more tolerable compared to upper GI en- doscopy and patients are more willing to utilize it for follow-up.

MDCT has high performance of in the detection and grading of Esophageal Varices in our study yet there is an increased risk of radiation hazard. with some limitations of MDCT when compared to upper GI endoscopy for the screening of Esophageal Varices and also; therapeutic intervention cannot be performed during MDCT, whereas this is possible during upper GI endoscopy.A dose-modulation program to reduce the dose of radiation.

Our study provided an oppor- tunity for cirrhotic patients for dual screening and evaluation strategy of two crucial pathological conditions, which are HCC and Esophageal Varices, without any added cost, effort, time or risk of radiation. Considering the high cost of performing 
multiple tests and the relative invasiveness of upper GI endoscopy, a single non-invasive surveillance tool for both Varices and HCC may be important. These factors constitute a major advantage of MDCT over upper GI endoscopy [19] .

In our study; the performance characteristics of MDCT have been proved to be superior to upper GI endoscopy for the detection and evaluation of other important extra- esophageal abnormalities, which were also considered other risk factors that needed rapid and selective management and may give further information regarding the propensity of Esophageal Varices and variceal bleeding such as splenomegaly, ascites, HCC and gastric submucosal Varices. This goes with Dessouky et al., [15] .

\section{Conclusion:}

MDCT with IV contrast is an excellent, safe, non-invasive alternative diagnostic tool for detection and grading of esophageal varices as compared to conventional upper GI endoscopy .

\section{References}

1- GARCIA-TSAO G. and BOSCH J.: Management of Varic- es and variceal hemorrhage in cirrhosis. N. Engl. J. Med., 362 (9): 823-32, 2010.

2- GOMEZ E.V., RODRIGUEZ Y.S., BERTOT L.C., et al.: The natural history of compensated HCV-related cirrhosis: A prospective long-term study. J. Hepatol., 58 (3): 43444, 2013.

3- FANTI L. and TESTONI P.A.: Sedation and analgesia in gastrointestinal endoscopy: What's new? World J. Gastroenterol., 16 (20): 2451-7, 2010.

4- CHERIAN J.V., DEEPAK N., PONNUSAMY R.P., et al.: Non-invasive predictors of esophageal varices. Saudi J. Gastroenterol., 17 (1): 64-8, 2011.

5- ELKAMMASH T., ELFIKY I., ZAITON F., et al.: Diagnostic performance of multidetector computed tomography in the evaluation of esophageal Varices. The Egyptian Journal of Radiology and Nuclear Medicine, 47 (1): 43-

51, 2016.
6- ZHAO L.Q., HE W., JI M., et al.: 64-row multidetector computed tomography portal venography of gastric variceal collateral circulation. World J. Gastroenterol., 16 (8): 1003-7, 2010.

7- HASHIZUME M., AKAHOSHI T. and TOMIKAWA M.: Management of gastric varices. J. Gastroenterol. Hepatol., 26 Suppl 1: 102-8, 2011.

8- SARANGAPANI A., SHANMUGAM C., KALYANASUNDARAM M., et al.: Noninvasive prediction of large esophageal varices in chronic liver disease patients. Saudi J. Gastroenterol., 16 (1): 38-42, 2010.

9- HWANG J.H., SHERGILL A.K., ACOSTA R.D., et al.: The role of endoscopy in the management of variceal hemorrhage. Gastrointest. Endosc., 80 (2): 221-7, 2014.

10- MORISAKA H., MOTOSUGI U., ICHIKAWA S., et al.: Association of splenic MR elastographic findings with gastroesophageal varices in patients with chronic liver disease. J. Magn. Reson. Imaging, 41 (1): 117-24, 2015.

11- POZA CORDON J., FROILAN TORRES C., BURGOS GARCÍA A., et al.: Endoscopic management of esophageal varices. World J. Gastrointest. Endosc., 4 (7): 312-22, 2012.

12- SINGEAP A.M., STANCIU C. and TRIFAN A.: Capsule endoscopy: The road ahead. World J. Gastroenterol., 22 (1): 369-78, 2016.

13- WELLS M.L., HANSEL S.L., BRUINING D.H., et al.: CT for Evaluation of Acute Gastrointestinal Bleeding. Radiographics, 38 (4): 1089-107, 2018.

14- MOFTAH S.G., KAMAL S. and HANNA A.: CT esophagography: Non-invasive screening and grading of esophageal Varices in cirrhosis. The Egyptian Journal of Radiology and Nuclear Medicine, 45 (2): 263-70, 2014.

15- DESSOUKY B.A. and ABDEL AAL EL S.M.: Multidetector CT oesophagography: An alternative screening method for endoscopic diagnosis of oesophageal varices and bleeding risk. Arab J. Gastroenterol., 14 (3): 99-108, 2013.

16- PERRI R.E., CHIOREAN M.V., FIDLER J.L., et al.: A prospective evaluation of computerized tomographic (CT) scanning as a screening modality for esophageal varices. Hepatology, 47 (5): 1587-94, 2008.

17- KIM Y.J., RAMAN S.S., YU N.C., et al.: Esophageal varices in cirrhotic patients: Evaluation with liver CT. AJR Am. J. Roentgenol., 188 (1): 139-44, 2007.

18- CANSU A., AHMETOGLU A., KUL S., et al.: Diagnostic performance of using effervescent powder for detection and grading of esophageal varices by multidetector computed tomography. Eur. J. Radiol., 83 (3): 497-502, 2014.

19- DENG H., QI X., ZHANG Y., et al.: Diagnostic accuracy of contrast-enhanced computed tomography for esophageal varices in liver cirrhosis: A retrospective observational study. J. Evid. Based Med., 10 (1): 46-52, 2017. 


\section{الملخص العربى}

\section{دراسة مقارنه بن الأشعه المقطعه متعددة الكواشف ومنظار المرئ في تقسم}

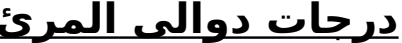

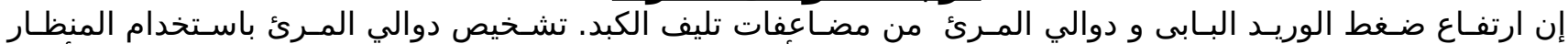

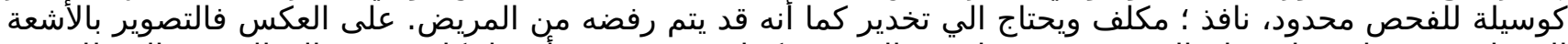

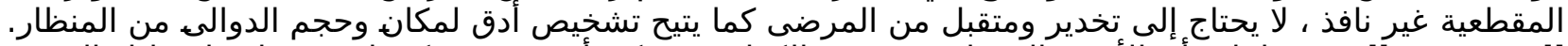

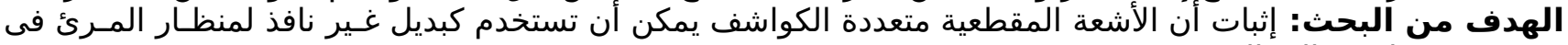
تشخيص درجات دوالي المرئ.

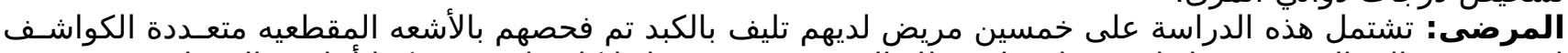

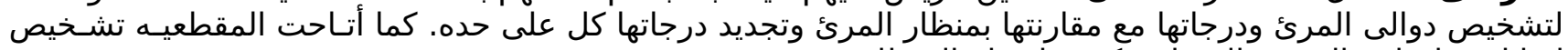

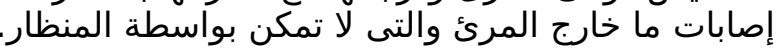

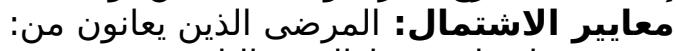
ارتفاع ضغط الاشنه: الوريد البابي. تليف بالكبد. سرطان الكبد.

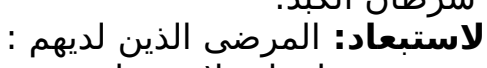

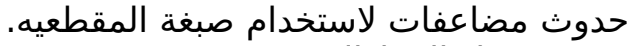

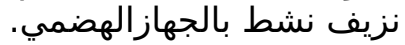
ربط دوالي المرئ بالمنظار.

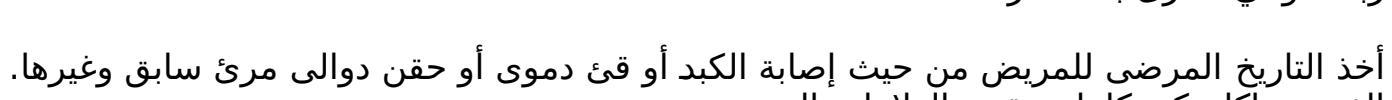

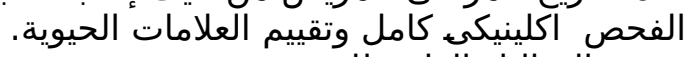

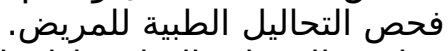

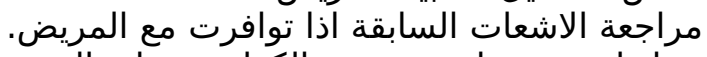

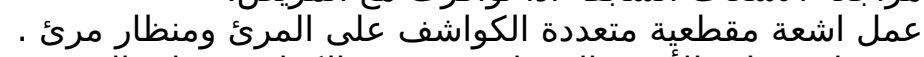

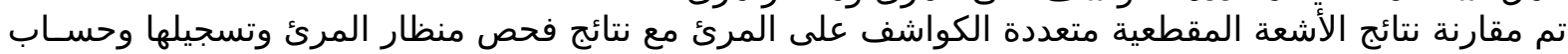

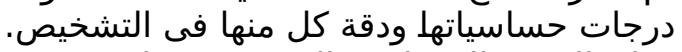

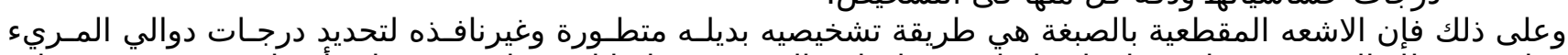

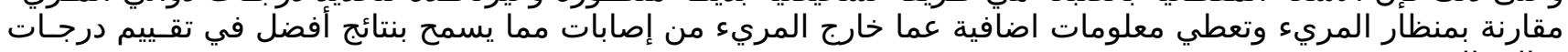
دوالي المريء. 